\title{
Focusing on the unexpected. Critical events as a step towards teachers' professional development
}

\author{
"Evangelia Kosmidou ${ }^{1}$ and Maria Sfyroera ${ }^{2}$ \\ ${ }^{1} \mathrm{PhD}$ Candidate, Faculty of Early Childhood Education, National and Kapodistrian University of Athens, \\ Greece \\ ${ }^{2}$ Associate Professor, Faculty of Early Childhood Education, National and Kapodistrian University of Athens, \\ Greece \\ *Corresponding author
}

\begin{abstract}
.
According to Woods (1993) critical events seem to awaken pupils' and teachers' creativity, mostly by drawing attention to incidents of everyday school life, otherwise remaining unnoticed. This study resulted from the analysis of part of the data of a larger research conducted in the context of a doctoral dissertation. Thirteen educators with different roles nine pre-school teachers, two critical friends, a $\mathrm{PhD}$ researcher and an academician - were involved in an action research program. As part of the research process, the teachers participating were invited to systematically identify, record and comment on "flash-points" arising from their everyday classroom experience with their students. Critical events recorded, should focus on either diversity issues or the impact of the research hypothesis approach. The research data were analysed mainly with qualitative methods since we were interested in understanding the meaning that teachers themselves attributed both to the critical events they selected to submit and to the way they believed that this practice affected their professional development. Quantitative method was also supportively used in order to receive measurable results for specific data. The analysis yielded interesting conclusions that highlight the use of critical events as a powerful and dynamic tool which seems to broaden teachers' overall understandings of their students and their educational context. Moreover, systematically spotting and commenting on critical events in everyday educational process seem to have contributed to improving teachers' reflective thinking, educational practices, thus, supporting their professional development.
\end{abstract}

Keywords: critical incidents, critical thinking, collaborative action research, reflective pedagogy, development of educational practices

\section{Introduction}

In this manuscript we will try to present a study concerning the role of using critical events (C.E.) as a tool towards teachers' professional development. The research was conducted in the context of a collaborative action research, where the two co-authors participated, the first as the facilitator-researcher and the second as the academic supervisor. The main focus of the initial research was to explore the possibilities and challenges derived from the educational 


\section{3rd International Conference on Innovative Research in}

\section{EDUCATION}

23-25 July 2021

Stockholm, Sweden

exploitation of the Persona Dolls (P.D.) approach ${ }^{1}$ towards managing student diversity and combating bias in preschool settings through the lenses of teachers themselves. For this purpose the nine preschool teachers involved became researchers of their own work. As identifying, describing and commenting on relevant critical events was part of their action research methodology, it gradually became evident -both to themselves and to the rest of the research team- that this practice started to alter their educational approach, thus contributing to their proffesional development. This realisation, often stated in a straitforward way by participant teachers, revealed a new field of research interest, where the systematic study of how reflecting on critical events affected teachers' understandings and overall educational perspective also became prominent.

The paper is divided in five main parts. The first part is the present introduction. The second part outlines the theoretical framework of using critical events in education. The third part presents the methodology, namely the purpose, the aims and the context of the research, as well as the research method. In the fourth part the main results of the study are discussed in an effort to cast light on the way the exploitation of critical events impacted on teachers proffesional identity in the context of the specific research. The conclusions are presented in the last part.

\section{The theoretical framework}

\subsection{Critical events in education}

The use of critical events or critical incidents have been popular in different disciplines (nursing, medicine, education etc) for a number of reasons, most of them related to the attempt to gain deeper insight into specific contexts (Shapira-Lishchinsky, 2011; Brookfield, 2015). In education and teaching, critical events are usually used by teachers or other related professionals as a reflective technique that helps them focus on their class and broaden their understanding about their students as well as their teaching practices (Tripp, 1993; Brookfield, 2015).

Brookfield compares teaching with white water rafting: "In both, periods of apparent calm are interspersed with sudden frenetic turbulence." (Brookfield, 2015, p.5). In a usual class unusual things happen all the time, although they are not always as noticeable or as obvious as the word "critical" predisposes us. In research terminology, critical events are determined as unplanned and unexpected incidents taking place in a certain context interpreted as challenging or significant or even extraordinary for a specific reason (Brookfield 1995; Woods 1993; Joshi, 2018). According to Woods (1993) they can be either negative or positive. In that sense, critical events are defined as such according to a certain standpoint. An incident is identified as critical

\footnotetext{
${ }^{1}$ Persona Dolls (PD) are special, life-like dolls, with their own personalities used as educational tools by teachers. The Persona Dolls approach aims at combating discrimination and promoting social justice in school, especially with younger children. It is method that uses life stories to develop empathy and other important social skills (Brown, 2001; Whitney, 1999).
} 
so long as the involved teacher considers it enlightens or reveals underlying aspects of their educational context. Different interpretations are also expected from different professionals.

\subsection{Critical events and teacher professional development}

It is evident from the above that a critical event is not always obvious to identify and certainly is not valued as important by everyone (Angelides, 2001; Woods, 1993). That is why teachers who lack relevant experience often find it difficult to get started. Tripp (1993) claims that critical events exist because we create them through analysis and critical thinking. However this is neither an easy nor a straightforward process. On the contrary, it entails careful observation, patience and open mind to see over everyday experience and keep descriptive notes, detailed enough to allow critical reflection after the events have occurred (Tripp, 1993; Woods, 1993)

Woods defines critical events in educational process along with teachers' professional development. He asserts that "They are flash-points that illuminate in an electrifying instant some key problematic aspect of the teacher's role and which contain, in the same instant, the solution." (Woods, 1993, p. 357). In such an approach teachers have to be prepared to challenge their certainties and rethink about their beliefs and practices in the light of the critical events analysis. Practising observation, note keeping and record analysing, though, entail adopting research methodology and, consequently, adopting relevant disposition and skills. Demanding, yet promising, the process is claimed to be rewarding for teachers who decide to use critical events as a method to improve teaching and learning experience in their settings (Angelides, 2001; Tripp, 1993; Woods, 1993)

\section{Methodology}

\subsection{The purpose and the aims of the research}

Our main purpose was to study the use of critical events as an educational methodological tool in relation to teacher professional development. More specifically, we were interested in answering the following questions:

- How do teachers themselves believe that the use of critical events impacted on their professional development?

- What does the study of the research material reveals about the way critical events written records impacted on teacher professional development in the context of the research project?

\subsection{The research context}

This study is part of a larger research conducted during the school year 2018-2019 in the context of a doctoral dissertation, which methodologically used collaborative action research approach. Nine preschool teachers, two critical friends and a research facilitator took part in an 


\section{3rd International Conference on Innovative Research in}

\section{EDUCATION}

23-25 July 2021

Stockholm, Sweden

anti-bias research project. They all worked together using the Persona Dolls approach as a research hypothesis for teachers handling diversity and challenging prejudice in their educational settings. The project lasted for almost a school year and included training sessions, collaborative experiential workshops, reflective writing as well as regular reflection and feedback team meetings. As part of the reflective process the participating teachers were asked, among others, to systematically write down and reflect on a number of critical events they spotted during their everyday school programme. The incidents should be relevant to the research lines and could either be discussed during reflective meetings with the whole team or, in some cases, teachers may receive feedback from the facilitator via telephone or email support.

\subsubsection{The participants}

Nine preschool teachers from different public settings in the region of Attica, participated in the research. Their selection was made through snowball sampling (Mason, 2002). Teachers were invited to participate in the research project, as long as they met the criteria of willingness to participate and commit themselves to the research obligations. Lack of significant previous involvement to a similar anti-bias training or action research project was also a requirement. The two critical friends involved in the research were also preschool teachers who for years have been researcher's academic and research partners. More explicitly, the participants in the research project were:

- The first author, as a facilitator and researcher

- Nine preschool teachers, as action researchers

- Two critical friends

The second author, as referred above, was the academic supervisor, acting mostly as a consultant as well as a more remoted critical friend for the researcher.

\subsubsection{The research timetable}

The research timetable, as it was developed during the larger research project is briefly presented in Table 1.

Table 1: The research timetable

\begin{tabular}{|c|c|c|c|}
\hline $\begin{array}{c}\text { October - } \\
\text { November } 2018\end{array}$ & $\begin{array}{c}\text { November } 2018 \text { - } \\
\text { January } 2019\end{array}$ & January - June 2019 & June 2019 \\
\hline $\begin{array}{l}\text { - Selecting } \\
\text { participant teachers } \\
\text { - First } \\
\text { communications } \\
\text { - Starting } \\
\text { questionnaires } \\
\text { - Starting focus } \\
\text { group }\end{array}$ & $\begin{array}{l}\text { Experiential workshops to } \\
\text { familiarise teachers with: } \\
\text { - The theoretical } \\
\text { framework of the } \\
\text { research } \\
\text { - The action research } \\
\text { methodology } \\
\text { - The Persona Dolls } \\
\text { approach }\end{array}$ & $\begin{array}{l}\text { Educational interventions } \\
\text { with the use of Persona Dolls } \\
\text { approach - record writing } \\
\text { (critical events and } \\
\text { educational intervention } \\
\text { records) } \\
\text { - Reflection and feedback } \\
\text { group meetings } \\
\text { - Telephone / on line support } \\
\text { - On site visits }\end{array}$ & $\begin{array}{ll}\text { Individual } \\
\text { interviews } \\
\text { - } & \text { Final group } \\
\text { evaluation } \\
\text { meeting } \\
\text { (focus group) }\end{array}$ \\
\hline
\end{tabular}

Source: Researcher's diary 


\subsubsection{The data}

The data used for this study come from different sources. They were collected from January to June 2019, namely from the beginning of teachers involvement in the record writing procedure to our final evaluation meeting in a focus group. More specifically, the data used were:

- Teachers'starting questionnaires

- The critical events the participating teachers handed in, in form of written records

- Teachers' individual interviews at the end of the research

- The final focus group interview with the whole team

- The researcher's personal diary notes

\subsubsection{Research method}

For the needs of this study, we used content analysis as it is appropriate for analysing research material coming from various sources (written, verbal, visual) and can combine both qualitative and quantitative approaches (Wilson, 2016). We considered that qualitative methods were more appropriate for the analysis of most of our research material since we attempted to produce convincing arguments for a specific "intellectual puzzle" (Mason, 2002). More specifically, we used thematic content analysis to elicit the meaning that emerged from the oral and written data in order to draw evident-based conclusions (Patton, 1990; Mason, 2002). A systematic effort was made to ensure that the categories were characterised by the criteria of internal homogeneity and external heterogeneity (Patton, 1990). At the same time, researcher's self reflection was an integrated part of the process analysis in order to minimise bias emerging from possible pre-understandings or pre-conceptions on the subject explored (Burnard, 1995; Mason, 2002). However, in parallel with the qualitative content analysis, the quantitative method was also used to a limited degree, as we were interested in obtaining measurable results for specific data, such as the demographics of the sample as well as information about the frequency and intensity of the ideas, perceptions, etc expressed in the oral and written texts (Wilson, 2016).

As part of the process, all audio research data were converted into written texts so that they could be studied and coded along with the written ones. Then, after reading many times and carefully studying all the data, we tried to classify them into categories in order to produce meaningful answers to the research questions (Mason, 2002).

\section{Results}

\subsection{The teacher researchers}

As mentioned above, nine preschool teachers working in public settings from different municipalities of Attica, took part in the research project. They all expressed their willingness to participate and commit themselves to the research purpose and procedures. The analysis of their starting questionnaires showed their interest in the subject as well as their lack of previous 


\title{
EDUCATION
}

23-25 July 2021

\author{
Stockholm, Sweden
}

involvement in relevant projects or training. As far as the demographics are concerned, data processing showed that all teachers were above thirty one years old (Figure 1).

Figure 1: Teachers' age

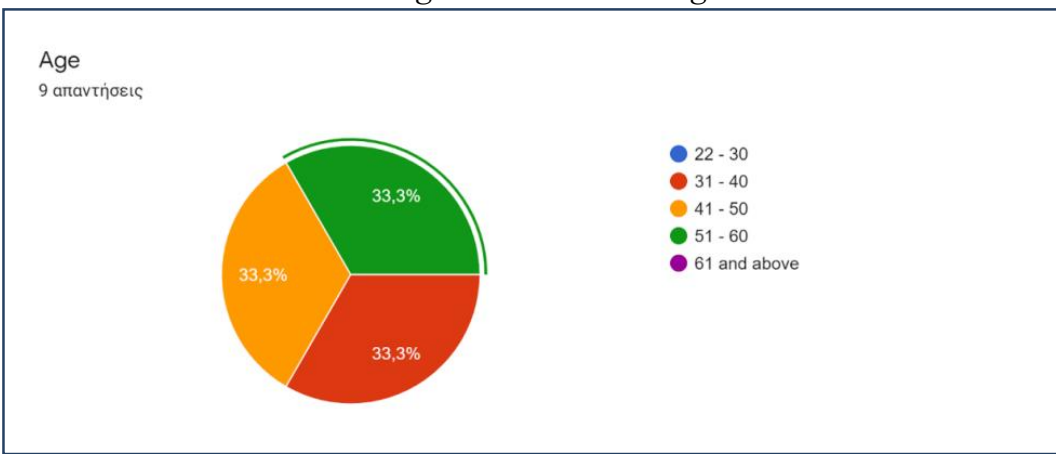

Source: Starting questionnaire

Regarding their level of studies, five of them held a postgraduate diploma (M.A. or other post-university training), while all the others were university graduates.

Figure 2: Teachers' level of studies

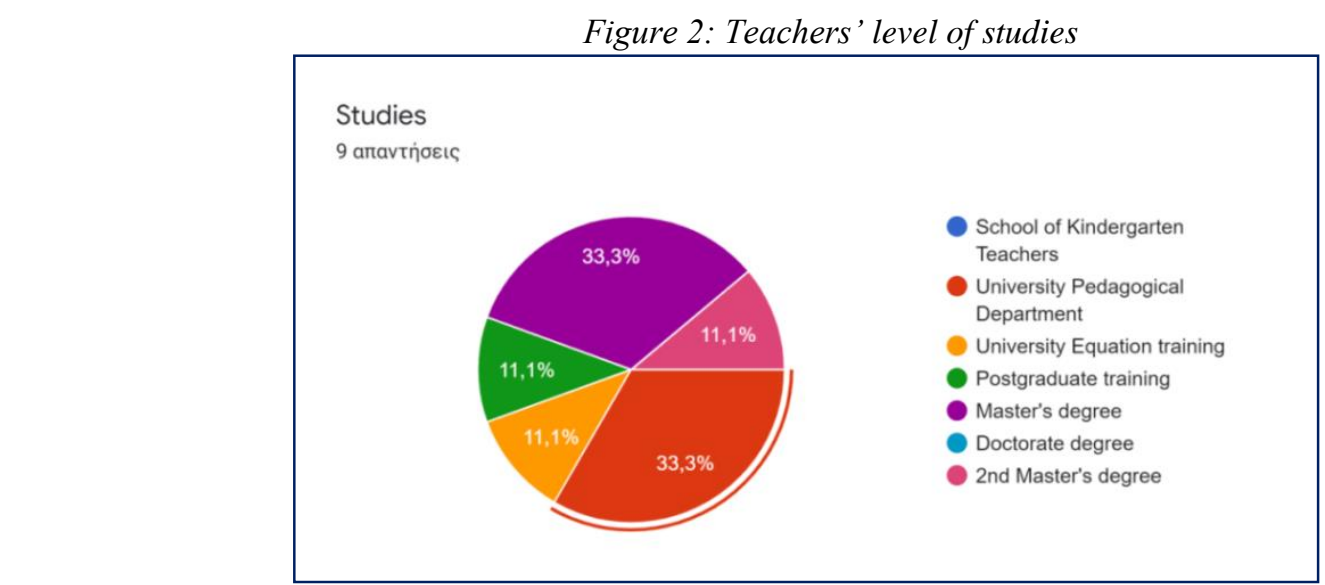

Source: Starting questionnaire

As depicted in Figure 3, entering the research project, all participants had been working as teachers for at least eleven years, some even for almost thirty years. 


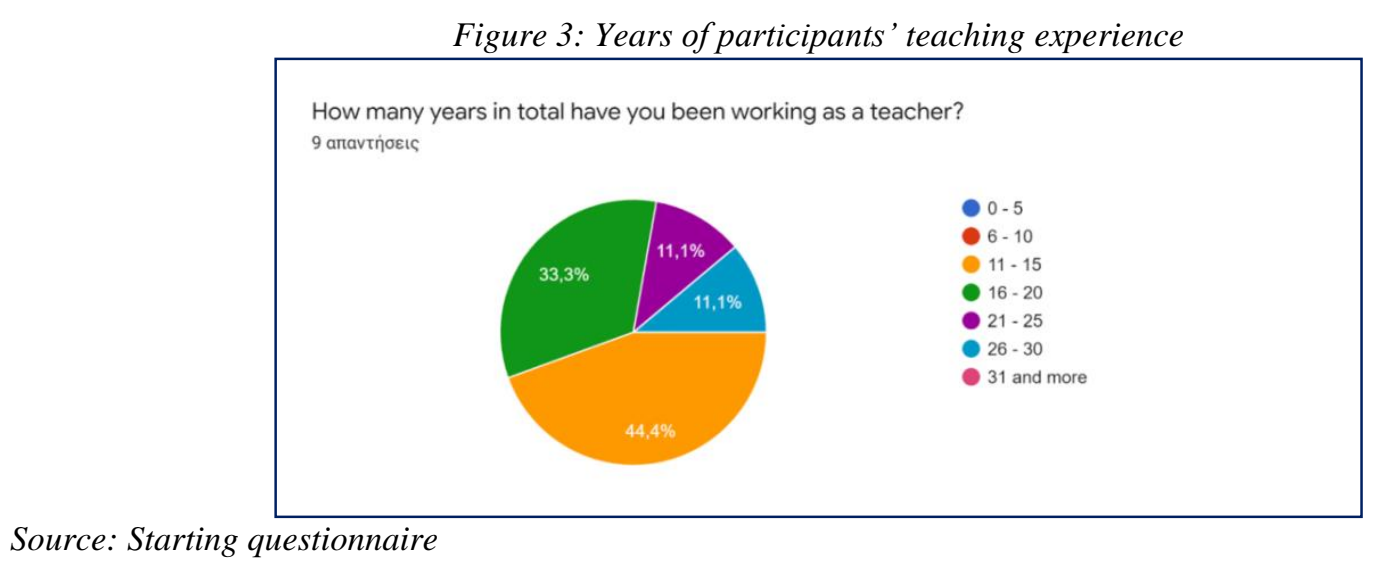

\subsection{Using critical events as an educational tool: pros and cons}

In the context of the training workshops that preceded the educational interventions, the teachers participating were involved in experiential workshops. They were introduced to the rationale of critical events in an effort to become familiar with useful methodological tools that could support them in approaching their role as teacher-researchers. In this perspective, a brief presentation of the relevant theoretical and methodological framework was made, enriched by discussions over examples of critical events from real school settings. Following these workshops, teachers were first encouraged to practise the process, by observing their context, keeping notes and to spot and record critical events relevant to the axis of diversity. As soon as teachers started to make their educational interventions using the Persona Dolls method as an anti-bias approach, they were asked to submit their critical events in written forms, now focused on two axes: incidents connected to a) diversity issues and b) the use of the Persona Dolls approach in terms of dealing with it. In order not to put teachers in a stressful situation and jeopardise the momentum that seemed to be developing in the research project, we kept training in the recording and analysis of critical events brief ${ }^{2}$. However, in addition to the initial presentations, bibliography was provided and there was continuous personal or team feedback on how to enrich their understanding of the recordings submitted throughout the project. As part of the research, each teacher had to submit at least one critical event per week. The total number of critical events submitted is presented in Table 2.

\footnotetext{
${ }^{2}$ Such training in research methodology would itself require a lot of time, something that did not coincide neither with the participants' expectations nor with the direction of the research, since we did not seek to be carried out by teachers who would be familiar with the use of research tools.
} 


\section{3rd International Conference on Innovative Research in}

\section{EDUCATION}

23-25 July 2021

Stockholm, Sweden

Table 2: Number of critical events and educational interventions per teacher

\begin{tabular}{|l|l|l|l|l|l|l|l|l|l|l|}
\hline Teachers & N1 & $\mathbf{N 2}$ & $\mathbf{N 3}$ & $\mathbf{N 4}$ & $\mathbf{N 5}$ & $\mathbf{N 6}$ & $\mathbf{N 7}$ & $\mathbf{N 8}$ & $\mathbf{N 9}$ & Totals \\
\hline $\begin{array}{l}\text { Critical events } \\
\text { submitted }\end{array}$ & 3 & 17 & 15 & 16 & 16 & 15 & 15 & 19 & 11 & 127 \\
\hline $\begin{array}{l}\text { Educational } \\
\text { interventions }\end{array}$ & 12 & 16 & 16 & 16 & 15 & 16 & 15 & 15 & 13 & 134 \\
\hline
\end{tabular}

Source: Critical events records submitted

Despite their initial agreement, two teachers did not submit the minimum number requested, although they reported they had identified and kept notes for more critical events. The analysis shows that the reasons for this are mainly connected to a number of practical and methodological difficulties they faced, presented below.

\subsubsection{Facing the challenges}

From the analysis of the data it appears that using critical events in the daily school practice was often a challenging process for teachers. For most them it involved both practical and methodological difficulties, the overcoming of which was not always an easy task. Three of the participant teachers claim that the process of writing and reflecting on critical events was time consuming.

"To write down the records, you need to devote time" (N4, final focus group)

$\mathrm{N} 1$ and N9 actually attribute the fact they did not finally submit the required number of critical events - even though they had spotted more - to lack of adequate time to record them.

"It was rather hard to arrange my time... When I sat down to write them down and it wasn't immediate, i.e. within a day or two, at most, I think I lost something, something was missing ...." (N1, interview)

Both during the individual interview and the closing focus group, some teachers refer to the methodological difficulties of spotting critical events and commenting on them.

"It was hard for me to write down... I was afraid of missing something and I had to record exactly the incident in the description, just as the dialogues happened, how, where we were, ...verbatim dialogues were difficult for me... not to forget or put something of my own, which had not been said." (N7, interview)

On the other hand, despite any inconvenience they felt, the analysis of their manuscripts showed that they could all spot critical events relevant to the research axes. Also, they would quite efficiently describe the flash points they selected.

"How do you think Akis ${ }^{3}$ felt when he could not write his name, while his other classmates did?" Nikos starts spinning in his seat and tries to speak, addressing me. At that moment, the

\footnotetext{
${ }^{3}$ Akis and Thrasos are some of the names of the PDs used by teachers in the context of the research project.
} 


\section{3rd International Conference on Innovative Research in EDUCATION}

23-25 July 2021

Stockholm, Sweden

words "sucks", "very bad", "too bad" are heard in the classroom in the form of a brainstorm. Nikos has risen from his seat, standing in front of me and addressing Akis he says in a whisper: "Akis, Akis, can I tell you?..." (N2, C.E., descriptive part, 1/2/2029)

However, the theoretical quality of their interpretation and comments on the events, especially at the beginning, seems to be partly related to their prior familiarity with similar methodological practices ${ }^{4}$

"...I noticed Nikos trying to make eye contact with me, coming down from his seat and standing in front of me. The feeling he causes me is irritability and anxiety that he is distracting the children or that, by his behaviour, he will steer the conversation towards literacy issues. His attitude to criticise Akis's difficulties as well as to disrupt the process, makes me angry. Although I try to bring him back to the process politely, I feel that my patience is being tested by his frequent interruptions." (N2, commentary part, 1/2/2029)

On the other hand, participants who were first met with the role of teacher-researcher found it more difficult to make reflective comments, especially at the beginning. This is evident both through their speech and in their writings:

"I was troubled by... about documenting the commentary on critical events, that is, methodological things. ... at the beginning, the first events, the commentary is completely off" (N4, interview)

"Observing the dialogue between the children, I found that there is the perception that "... it is not right for boys to do certain jobs!" Knowing, from discussions with both his parents, that M. 's environment does not cultivate such stereotypes, I was troubled..." (N1, C.E., commentary part, 15/1/2019)

All teachers mentioned that much of their difficulty emerged from their actually ignoring the way of observing and reflecting both on their class and their own practice.

"At the beginning, it was very difficult to spot critical events because I had not learned to observe my team. In the process, however, this was slowly, not completely resolved, but I was certainly now able to identify critical events more easily...." (N7, interview)

\subsubsection{Realising the benefits and prospects}

As the research project was developed, teachers gradually started acknowledging the significance of carefully observing everyday school process and paying attention to small incidents connected to the research axes, until then remaining unnoticed.

\footnotetext{
${ }^{4}$ Possibly through postgraduate studies
} 


\section{3rd International Conference on Innovative Research in}

\section{EDUCATION}

23-25 July 2021

Stockholm, Sweden

"Things were emerging that... What do boys and girls do? I thought this would never exist in my class, and yet it emerged. Being fat... racism in terms of... with regard to the different communities, the Roma, all this, I thought would not emerge..." (N3, interview)

"In a conversation with the children about how they felt about Landrine, the new Congolese pupil in our class, Criton says, "Landrine is from another country and has got dark skin." Helen then pops up and says, "And you have darker skin." And he replies, "I'm like this, because I've been sitting in the sun for a long time. While those who have different skin colour are not normal people." Then, I... ask him, "What do you mean they're not normal people?" And I ask him again: "So the British, for example, are not normal people?" To my question, "who are normal people", my children replied: "Those who walk, talk, eat, drink, think." (N5, C.E., descriptive part, 25/1/2019)

Although the research axes formed the starting point for their written records, the analysis reveals that the exploitation of critical events influenced teachers' overall perspective in relation to their class and their work in it. They all emphatically mention that this methodological tool has significantly helped them to get to know their students better and to gain a deeper insight into the context of their class.

"...it was what opened my mind ... about how my team works. I got information that I might not get in any other way...it helped me to see many different things very differently and to discover details that I had never noticed in myself and my team, even with my colleagues "(N1, interview)

"It was a picture of my class, like a photo album ... I could understand better what my kids had in their mind or how they perceive things. There... This has been the help critical events gave me." (N8, interview)

Teachers, thus, seem to gradually realise that critical events offer them much information about their context needs which can be used in a number of different ways. Most participants report that keeping records of important flashpoints acted as useful memos, helping them not to forget or overlook important issues arisen.

"I could look back at something I'd forgotten because otherwise I might have put it aside or whatever." (N7, interview)

Moreover, the analysis shows that critical events often became starting points for new educational action, including lesson planning. According to the relevant data, all participant teachers stated in some way that they were planning to exploit or already had exploited the information emerged from recorded incidents in their educational programme. Activities planned were often connected to the Persona Doll approach and the research axes:

"...I am thinking of designing a PD intervention related to colour or some other physical characteristics that will include Akis into a group, for which there will also be negative beliefs, in order to discuss how false perceptions leading to marginalisation can be created." (N2, C.E., commentary part, 20/5/2019) 
"In other words, I would like to collect critical events and manage them in class at some point." (N3, final focus group)

or even used as bases for educational interventions related to other thematics.

"Of course it makes sense to take the information and somehow use it. As a result, it gave me ideas to create other activities, whether supportive of the issue we had discussed, or ...to see how I could take it a little further." (N1, interview)

"I therefore thought of introducing activities through which I would discuss with the children of my group the issue of name-calling and generalising and their emotional impact. Initially, I designed activities for a thematic on identity and positive self-image, based on a children's literature book that I have also dealt with in a previous school year..." (N2, C.E., commentary part, 4/4/2019)

\subsubsection{Reflecting on critical events}

A thorough study of the critical events shows that as the research programme progresses, teachers' effort to deepen their interpretative comments is evident along with the evolution of their (self) reflection. In fact, it seems that critical events are gradually being exploited by the latter as opportunities to focus more carefully on their students, combining what they observe with the information they already have about them. Thus, in the descriptive part critical events provide information on the issues that emerge in the classroom in relation to diversity issues. On the other hand though, the commentary part in most records begins to reveal a process of enriching, comparing and reframing teachers' own perceptions of the way they think about their students as well as their practices and their role in the educational process.

Quite often the process of reflection on critical events challenges teachers' perceptions of their class:

"The reason I chose this event as critical is that I did not expect children to avoid going to a party for socio-economic reasons. While it would be expected that they would like to go to that party to have fun with their friends, eat cake and food and get together outside school, they preferred to refrain from it considering that their appearance in a new good outfit is more important, since otherwise they might receive mocking comments....Through this example it is apparent how important they consider others' opinion about their appearance to be and how materialistic and self-centered our society has become..." (N5, C.E., commentary part, 4/4/2019)

As mentioned above, trying to get to know their students better, teachers also reflect both on the way they think and act and on their own role in managing diversity issues either when planning and organising interventions with the Persona Dolls approach or during their educational programme in general. From their record analysis it is evident that all participants are gradually adopting a more reflective interpretation of the critical events they identify. In this context their comments are becoming more self-referential with an apparent attempt to review their perceptions and their practices in the light of their understandings. 


\title{
3rd International Conference on Innovative Research in
}

\section{EDUCATION}

23-25 July 2021

\author{
Stockholm, Sweden
}

"And maybe mine. Not maybe! And mine... and in speech, because our speech often hides racial stereotypes but also in certain behaviours. ... The boy you're giving a man's role: "You, who are stronger, go fetch the chair". Things very easily coming out, but in the end... they pass in their own way, in an indirect way, a stereotype to children. Or they keep using it, when you as a teacher should do everything you can to undo it." (N4, interview)

"I chose this as a critical event from today's visit of Thrasos because F. and ... K. are two tough children who repeatedly insult their classmates either for their appearance or for their painting saying that "what you made sucks!" ...we have discussed that we should be polite and not offend others because this makes them feel bad and makes them sad. I thought I'd been able to get kids to understand that, and I had never heard it happen again. - I guess I didn't make it after all... -It may have happened before and I didn't realise it... -What is going on with these kids and they behave in such a rude and ugly way to their classmates? -What else could I do to help these two children?" (N7, C.E., commentary part, 10/5/2019)

Similarly, N9 comments on the contribution of critical events to these realisations and the need to reflect on her educational practices in a perspective of exploiting her understandings:

"So I think about how important it is to use methods and create in the classroom the "atmosphere" that will automate an alternative attitude towards diversity. Activities where children have the opportunity to develop relationships, groups and, therefore, feelings of solidarity and empathy. Are these activities my first concern in the school routine? How much time do I really give for children to think about solutions and discover how to manage the problems that arise by themselves?" (N9, C.E., commentary part, 9/4/2019)

It is also interesting to note that in some cases, the reflection concerns "pleasant" surprises, causing small or bigger "cracks" in teachers' previous perceptions of their class.

"Sophia's initial idea and other children's ideas that followed revealed to me that children in my group could express deeper levels of empathy than I expected. ...children exceeded my expectations." (N2, C.E., commentary part, 8/584/2019)

As some of them claim, focusing on positive flashpoints was equally important when reflecting on the educational process. Identifying and commenting only on negative events deprived them of paying attention to important elements of everyday school life.

"Then I really realised... how important it is to record them, again on many levels, because very positive things do come out through all these processes that were not recorded in my mind because I had in mind that critical event is only the negative" (N6, interview)

Taking distance from the events and reconsider them later was another reflective practice teachers seem to have adopted, as the analysis shows.

"It is not that I hadn't notice them, but I was handling them differently... When something happened, I would intervene immediately so as to manage it and see how we could solve it. By this process, I realised that as you leave it (for a while) and relax, it's more possible to manage it better" (N3, interview) 
Finally, one crucial research finding is that all teachers recognise that using critical events generally opened for them a new way of approaching and analysing incidents arising in everyday school life and therefore they acknowledge its significance as an educational tool.

"The critical event... the methodology of how to record and why -this is a critical event -is very important for almost anything. I wish we could write critical events all day." (N2, interview)

"I was able to see with another eye the context of my class... I saw... deeper into where each child comes from. What can what they said mean?" (N3, interview)

\section{Conclusion}

The study of the research material, within the framework of the specific research, revealed important elements that highlight the role of critical events as important methodological tools in everyday educational practice and their contribution to participant teachers' professional development. The analysis showed that their involvement in the process of recording critical incidents seem to have improved their abilities to focus on their context and evolved their observing and reflecting skills. Overcoming the practical and methodological difficulties some of them faced, especially at the beginning of the research project, all teachers acknowledge through their speech and writings- this development and they clearly recognise the impact of critical events exploitation on it. As emerged from data analysis their involvement in reflection processes gradually broadened their understandings on their students and their own role in the educational process. Adopting action research practices, they gradually became researchers of their own context: they attempt to see behind the obvious and discover less visible, however, important aspects of everyday life in their settings, in order to better manage them. All in all, the whole process seems to be leading them to small cracks in their educational perceptions and, consequently, affect their practices on the basis of their conclusions.

\section{References}

Angelides, P. (2001). The development of an efficient technique for collecting and analyzing qualitative data and the analysis of critical incidents. International Journal of Qualitative Studies in Education. 14(3) pp. 429-42.

Brookfield, S. D. (2015). The skillful teacher. On Technique, Trust, and Responsiveness in the Classroom. San Francisco: Jossey Bass.

Brown, B. (2001) Combating discrimination; Persona dolls in action. Stoke on Trent: Trentham Books.

Burnard, P. (1995). Interpreting text: an alternative to some current forms of textual analysis in qualitative research. Social sciences in Health. 1. pp. 236-245.

Mason, J. (1996). Qualitative Researching. London: Sage Publications.

Joshi, K. R. (2018). Critical Incidents for Teachers' Professional Development. Journal of NELTA Surkhet. 5. pp. 82-88. 
3rd International Conference on Innovative Research in

\section{EDUCATION}

23-25 July 2021

Stockholm, Sweden

Patton, M. Q. (1990). Qualitative evaluation and research methods. CA: Sage Publications.

Shapira-Lishchinsky, O. (2011). Teachers' critical incidents: Ethical dilemmas in teaching practice. Teaching and Teacher Education. 27. pp. 648-656.

Tripp, D. (1993). Critical incidents in teaching. Developing professional judgment. Routledge.

Wilson, V. (2016). Research Methods: Content Analysis. Evidence Based Library and Information Practice. 11(1). pp.41-43.

Whitney, T. (1999) Kids Like Us: Using Persona Dolls in the classroom. St. Paul: Redleaf Press.

Woods, P. (1993). Critical Events in Education, British Journal of Sociology of Education. 14(4). pp. $355-371$. 